\title{
Geoecologia das paisagens e planejamento ambiental: discussão teórica e metodológica para a análise ambiental
}

\author{
Geoecologia de los paisajes y planificación ambiental: discusión teórica y metodológica \\ para el análisis ambiental
}

\section{Nágila Fernanda Furtado Teixeira ${ }^{1}$, Edson Vicente da Silva ${ }^{2}$ e Juliana Felipe Farias ${ }^{3}$}

\author{
1 Mestranda em Desenvolvimento e Meio Ambiente-PRODEMA/Universidade Federal do Ceará. E-mail: fernandaft92@gmail.com \\ 2 Professor do Departamento de Geografia/Universidade Federal do Ceará. E-mail: cacauceara@gmail.com \\ 3 Professora do Departamento de Geografia/Universidade Federal do Rio Grande do Norte. E-mail: julianafelipefarias@yahoo.com.br
}

RESUMO: Este trabalho discute a Geoecologia das Paisagens e planejamento ambiental para análise ambiental. Parte do debate da paisagem como conceito inerente a Geoecologia, apresentando geossistema e aporte teóricometodológico. Discute fundamentos, categorias, aplicabilidade, planejamento e zoneamento ambiental, objetivando análise ambiental. Baseada no referencial teórico-metodológico da Geoecologia das Paisagens se analisa ambientes em diferentes escalas: local, municipal, regional ou nacional, com a divisão das unidades geoecológicas e análise integrada das condições ambientais e socioeconômicas. O diagnóstico do uso-ocupação, limitações e potencialidades permitirá conhecimento da área e a determinação de zonas ambientais de acordo com a vocação e o diagnóstico realizado.

Palavras-chave: Geoecologia das Paisagens. Planejamento ambiental. Zoneamento.

\begin{abstract}
This work discusses Geoecology of Landscapes and environmental planning for environmental analysis. Part of the landscape debate as an inherent concept in Geoecology, presenting a geosystem and theoreticalmethodological contribution. It discusses fundamentals, categories, and applicability, planning and environmental zoning, aiming at environmental analysis. Based on the theoretical and methodological reference of Geoecology of Landscapes, different environments are analyzed at different scales: local, municipal, regional or national, with the division of geoecological units and integrated analysis of environmental and socioeconomic conditions. The useoccupancy diagnosis, limitations and potentialities will allow knowledge of the area and the determination of environmental zones according to the vocation and the diagnosis made.
\end{abstract}

Keywords: Geoecology of Landscapes. Environmental planning. Zoning.

Sumário: Introdução - 1 A Paisagem como Objeto de Estudo Geográfico - 2 Planejamento e Zoneamento Ambiental: Aspectos teóricos e conceituais - 3 O Geossistema e a Geoecologia das Paisagens - Considerações Finais - Referências. 


\section{INTRODUÇÃO}

A Geografia é a ciência que estuda, entre outras questões, a sociedade e as modificações que estes desenvolvem na paisagem, a partir da dinâmica antrópica de construção, reordenamento dos espaços físicos e atividades econômicas. Durante muito tempo, a geografia física setorizou a análise dos componentes naturais, entendeu-os de maneira separadas. No entanto, com o advento da temática ambiental e da necessidade de inter-relacionar sociedade e natureza emergiu, pautada no geossistema, a análise ambiental.

Tal abordagem refere-se à realização dos diagnósticos, zoneamentos e avaliação de impactos ambientais, bem como o manejo dos recursos naturais e planejamento dos usos dos espaços naturais com a finalidade de proteger os sistemas ambientais (SALES, 2004).

$\mathrm{Na}$ atualmente, a geografia física aplicada estuda os aspectos físico, naturais, bióticos e socioeconômicos na perspectiva da análise ambiental integrada, voltada a compreender os problemas socioambientais como os relacionados ao planejamento ambiental, com o suporte dos zoneamentos (ROSS, 2009). Para tanto, despontam novas bases teóricas e metodológicas aos estudos ambientais e socioambientais. Destaca-se a Geoecologia das Paisagens como instrumento para a compreensão do meio natural e social e sua inter-relação a partir de uma visão geossistêmica e procedimentos organizados de pesquisa.

Assim posto, essa metodologia volta-se a subsidiar o planejamento ambiental em diferentes escalas: local, municipal, regional e nacional, por meio do zoneamento ambiental para ordenar as zonas de acordo com as potencialidades, limitações e problemas ambientais.

Nessa perspectiva, o presente artigo objetiva realizar uma discussão teórica e metodológica sobre a Geoecologia das Paisagens e o planejamento ambiental para a análise ambiental. Primeiramente, discute-se o conceito de paisagem, a evolução da ciência da Paisagem e sua importância para o aporte teórico-metodológico em questão. Ademais, aborda-se o planejamento e o zoneamento ambiental como instrumento da organização e disciplinamento de áreas de acordo com a vocação e a realidade diagnosticada. Finaliza-se com o debate sobre o geossistema e a Geoecologia das Paisagens com a descrição dos procedimentos metodológicos de pesquisa.

\section{A PAISAGEM COMO OBJETO DE ESTUDO GEOGRÁFICO}

A paisagem é um espaço físico resultante de processos naturais, antrópicos e antroponaturais ao longo do tempo. Assim, é tudo aquilo que é perceptível aos olhos, formado por um conjunto de elementos em uma porção qualquer do planeta (MENDONÇA, 1992). No imaginário coletivo, esse conceito relaciona-se a pintura e ao visível, sendo muito utilizada por diferentes áreas do conhecimento, Biologia, Arquitetura e a Geografia.

Etimologicamente, o termo paisagem surgiu no século XVI relacionada a países, denotando o sentido de região, território, nação. Esse conceito pode ser caracterizado historicamente sob duas perspectivas: I) estética-fenomenológica, em que a paisagem se relaciona a aparência e representação como um arranjo dos objetos visíveis pelo sujeito e II) geopolítica, 
percebida como uma unidade territorial onde se desenvolve a vida em comunidades humanas (VITTE, 2007).

O conceito de paisagem foi tratado de maneira diferente pelas várias correntes da geografia, sofrendo influência dos estudiosos e do contexto histórico-cultural. As primeiras noções de paisagem foram elaboradas por Humboldt, denominada Landschaft que posteriormente foi ampliada por estudiosos como Dokuchaev, Passarge e Berg no final do século XIX e início do XX. A paisagem era entendida como a interação entre os elementos físicos naturais: clima, rocha, relevo, solo e vegetação (RODRIGUEZ; SILVA, 2002).

No início do século XIX, Humboldt estabeleceu o conceito de paisagem no sentido natural e estético, influenciado pela filosofia da natureza, conhecimento proveniente da simples observação da natureza, permitindo desvendá-la até a essência das coisas e possuía a necessidade de poetizar as ciências (GOMES, 2000).

Ainda no século XIX, Dokoutchaev ofereceu importante contribuição para a ciência da Paisagem. Ele denominou de complexo natural territorial, a interação de componentes bióticos e abióticos que se desenvolvem no interior de um complexo sistêmico (CAVALCANTI, 2006). Ritter, baseado na noção de região, discutiu a relação sociedade-natureza no qual o homem era o centro e o elemento essencial na modelagem dos sistemas terrestres. Suas ideias foram aperfeiçoadas por Paul Vidal de La Blache (RODRIGUEZ; SILVA, 2002).

A visão antropocêntrica de La Blache acentuou a separação entre os elementos físiconaturais e os elementos humano-sociais das paisagens ao considerar o ser humano como agente principal na modelagem do planeta Terra (MENDONÇA, 1993). Outra percepção, desenvolvida pelos alemães, entendida a paisagem como o conjunto de elementos do meio natural e proveniente das ações humanas, dividida em paisagem natural e paisagem humanizada ou antrópica.

Geógrafos alemães, discutiam a paisagem, landschaft, com a incorporação de um elemento novo, a sociedade, assim, teceu a base ao surgimento do conceito de paisagem cultural (MENDONÇA, 1992). Ainda aqui, a paisagem apresenta a complexidade da análise integrada ao relacionar o meio natural e a cultura. A noção de paisagem cultural foi desenvolvida por Carl Sauer nos anos 20 do século XX, em que existia a paisagem natural, original que não sofreu modificações antrópicas e a paisagem cultural formada pelas ações humanas. "A paisagem cultural é modelada a partir de uma paisagem natural por um grupo cultural em que a cultura é o agente, a área natural é o meio e a paisagem cultural o resultado" (SAUER, 1998, p. 59).

Na década de 1960, Sotchava realizou estudos sistemáticos com o objetivo de aplicálos ao planejamento territorial, baseado na Teoria dos Sistemas e considerando a landschaft, paisagem, como um sistema interligado e organizado com influência socioeconômica. A paisagem é uma categoria do geossistema, fruto das relações e integração dos elementos, relação homem-sociedade, biota-ambiente, dentre outras que formam esse sistema (RODRIGUEZ; SILVA; CAVALCANTI, 2013). Assim, a ciência da Paisagem como disciplina científica que estuda a paisagem percorreu algumas etapas (Quadro 1) até se configurar como um sistema de método, procedimento e técnica de investigação. 
Quadro 1- Evolução da Ciência da Paisagem como disciplina científica

\begin{tabular}{|l|l|}
\hline \multicolumn{1}{|c|}{ ETAPAS } & \multicolumn{1}{c|}{ DESCRIÇÃo } \\
\hline $\begin{array}{l}\text { Gênese } \\
(1850-1920)\end{array}$ & $\begin{array}{l}\text { Surgem as primeiras ideias físico-geográficas sobre a interação dos fe- } \\
\text { nômenos naturais e as primeiras formulações da paisagem como noção } \\
\text { científica. }\end{array}$ \\
\hline $\begin{array}{l}\text { Desenvolvimento bio- } \\
\text { geomorfológico } \\
\text { (1920-1930) }\end{array}$ & $\begin{array}{l}\text { Influenciado por outras ciências, desenvolveu-se as noções de interação } \\
\text { entre os componentes da paisagem. }\end{array}$ \\
\hline $\begin{array}{l}\text { Concepção físico- } \\
\text { geográfica } \\
\text { (1930-1955) }\end{array}$ & $\begin{array}{l}\text { São desenvolvidos os conceitos sobre a diferenciação em pequena escala } \\
\text { da paisagem (zonalidade e regionalização) }\end{array}$ \\
\hline $\begin{array}{l}\text { Análise estrutural- } \\
\text { morfológica } \\
\text { (1955-1970) }\end{array}$ & $\begin{array}{l}\text { Volta-se a atenção para a análise dos problemas de nível regional e local } \\
\text { (taxonomia, classificação e cartografia) }\end{array}$ \\
\hline $\begin{array}{l}\text { Análise funcional } \\
\text { (1970- até hoje) }\end{array}$ & $\begin{array}{l}\text { São introduzidos os métodos sistêmicos e quantitativos e desenvolvida a } \\
\text { Ecologia da Paisagem }\end{array}$ \\
\hline $\begin{array}{l}\text { Integração geoecológica } \\
\text { (1985- até hoje) }\end{array}$ & $\begin{array}{l}\text { Volta-se a atenção para a inter-relação dos aspectos estrutural-espacial e } \\
\text { dinâmico-funcional das paisagens e a integração em uma mesma direção } \\
\text { científica (Geoecologia ou Ecogeografia) das concepções biológicas e } \\
\text { geográficas sobre as paisagens }\end{array}$ \\
\hline
\end{tabular}

Fonte: RODRIGUEZ; SILVA; CAVALCANTI, 2013.

No Brasil, Ab'Saber em 1969 ofereceu a maior contribuição aos estudos sobre paisagens naturais promovendo uma renovação metodológica e instrumental nas pesquisas geomorfológicas. Esse autor entendia a paisagem como sendo o resultado de uma relação entre os processos passados e os atuais (VITTE, 2007).

Cavalcanti (2006) salienta que a ciência da paisagem está direcionada a análise ambiental e como objeto de estudo geográfico oferece contribuição essencial ao conhecimento da base natural, entendido como meio global e propicia fundamentos metodológicos importantes para o planejamento ambiental.

Nesse ínterim, o conceito de paisagem faz-se imprescindível para o desenvolvimento de pesquisas ambientais, pois, aliado aos preceitos da Geoecologia das Paisagens, representa o ponto de análise do meio natural e socioeconômico, a partir da investigação da paisagem natural e antrópica.

\section{PLANEJAMENTO E ZONEAMENTO AMBIENTAL: ASPECTOS TEÓRICOS E CONCEITUAIS}

A utilização e ocupação indevida dos espaços geográficos compromete a sustentabilidade ecológica em alguns setores, o que promove mudanças na dinâmica ambiental e no fluxo de matéria e energia, bem como no modo de vida das comunidades atingidas. Nessa perspectiva, faz-se necessário a implantação de propostas e ações voltadas ao planejamento ambiental, a partir de uma análise detalhada das características naturais e socioeconômicas, voltadas ao uso sustentável dos recursos naturais e mitigação de problemas ambientais diagnosticados. 
O termo planejamento apresenta diferentes definições, dependendo do tipo: governamental, ecológico e familiar e do campo de conhecimento que a utilize: arquitetura, direito, geografia. Dentre os diferentes tipos de planejamento destaca-se o planejamento ambiental que pressupõe estabelecer a organização funcional e espacial de determinadas áreas em dependência das características dos sistemas naturais, principalmente os ecos e os geossistemas (SILVA; RODRIGUEZ; LEAL, 2011).

Em outras palavras, o planejamento ambiental é o estudo que visa à adequação do uso, controle e proteção ao ambiente, com ênfase também no campo social e humano (SANTOS, 2004). De acordo com Rodriguez e Silva (2013, p. 133), "é um processo intelectual no qual são projetados os instrumentos de controle baseados em uma base técnico-científica, instrumental e participativa, o que deve facilitar a implementação de um conjunto de ações e processos de gestão e de desempenho".

O planejamento ambiental é considerado como: I) um instrumento da política ambiental em concordância com o modelo de desenvolvimento adotado; II) um suporte articulado ao processo de tomada de decisão; III) um exercício técnico-intelectual voltado para traçar as diretrizes e programar o uso do território, espaços, paisagens e características da gestão ambiental; iv) um rumo para inter-relacionar as ações dos agentes econômicos e os sistemas naturais (SILVA; RODRIGUEZ; LEAL, 2011).

Na perspectiva do planejamento econômico e ambiental do território, em escala municipal, estadual e federal é necessário que as intervenções antrópicas sejam planejadas com objetivos claros de ordenamento territorial, baseados nas potencialidades dos recursos naturais e humanos e as fragilidades dos ambientes naturais, valorizando a conservação da natureza para o desenvolvimento sustentável (ROSS, 2009).

Para o planejamento ambiental ser eficaz é necessário conhecer e entender as limitações, por meio de diagnósticos, potencialidades naturais do território, características físicas, naturais e as intervenções humanas nesse ambiente, a fim de propor a organização das atividades de acordo com a capacidade de suporte da natureza e que promova o desenvolvimento sustentável e comunitário.

Segundo Ross (2009), para o planejamento ambiental é preciso conhecer adequadamente o meio natural e a sociedade sob a perspectiva de que tanto a natureza quanto a sociedade apresentam uma funcionalidade específica. Assim, é preciso uma compreensão integrada da realidade socioeconômica, pela dinâmica dos processos de ocupação e das relações econômicas e sociais.

Assim, este está diretamente relacionado aos conceitos de desenvolvimento sustentável e multidisciplinaridade que exigem uma abordagem holística de análise dos elementos biológicos, físicos e socioeconômicos que possibilitem ações eficazes na solução dos problemas (SANTOS, 2004). Com efeito, permeia todos os níveis das relações sociais e econômicas das sociedades humanas e dos vínculos que estas estabelecem com a natureza (ROSS, 1997).

Para executar o processo de planejamento ambiental consideram-se, no mínimo, seis grandes enfoques (Quadro 2). 
Quadro 2 - Formas de interpretação e operacionalização do planejamento ambiental

\begin{tabular}{|l|l|}
\hline \multicolumn{1}{|c|}{ INTERPRETAÇÃO } & \multicolumn{1}{c|}{ MÉTODOS E FORMAS DE OPERACIONALIZAÇÃO } \\
\hline Geral & $\begin{array}{l}\text { Análise integrada das dimensões e os problemas. } \\
\text { Método Delfos-FOFA }\end{array}$ \\
\hline Ecossistêmica & Análise dos recursos bióticos e da biodiversidade \\
\hline Fatorial & Análise de componentes ambientais \\
\hline $\begin{array}{l}\text { Manejo de unidades de } \\
\text { conservação }\end{array}$ & $\begin{array}{l}\text { Análise das unidades de vegetação, do relevo, dos critérios e requisitos } \\
\text { das diferentes unidades de conservação }\end{array}$ \\
\hline Pesquisa-participação & Investigação dos desejos e pontos de vista da população local \\
\hline Geoecológicos & Análise dos potenciais e do estado das unidades geoecológicas \\
\hline
\end{tabular}

Fonte: RODRIGUEZ; SILVA; LEAL, 2011.

O presente artigo discute a interpretação geoecológica com o estudo das potencialidades, limitações e problemas ambientais das unidades geoecológicas para o planejamento ambiental de uma determinada área a fim de propor usos e ações voltadas ao desenvolvimento sustentável.

Para potencializar o planejamento ambiental faz-se necessário realizar o zoneamento ambiental, que de acordo com Farias (2012, p. 37) se configura "em um instrumento de apoio e orientação à gestão ambiental, capaz de fornecer direcionamentos programáticos e normas gerais para o disciplinamento dos usos dos recursos ambientais e da ocupação do solo".

O zoneamento é um suporte para o planejamento ambiental, estabelecido pela Lei $\mathrm{n}^{\circ}$ 6.938 de 1981, que estabeleceu a Política Nacional de Meio Ambiente (PNMA), ou seja, é um instrumento da política ambiental brasileira, o termo, posteriormente evoluiu para Zoneamento Ecológico-Econômico, incorporando as questões sociais e econômicas à ambiental. 0 zoneamento é a compartimentação de uma região em porções territoriais, delimitada no espaço, com estrutura e funcionamento uniforme. As zonas representam as potencialidades, vocações, fragilidades e suscetibilidade do território (SANTOS, 2004).

O zoneamento ambiental coleta e organiza dados sobre o território, propondo alternativas de uso para as unidades geoecológicas de acordo com a capacidade de suporte e tendência vocacional. Relaciona-se a definição de setores ou zonas a fim de proporcionar os meios para alcançar a conservação da natureza e a sustentabilidade do uso dos recursos naturais, servindo como prática fundamental ao desenvolvimento sustentável (SOUZA; OLIVEIRA, 2011).

Esse instrumento segue princípios norteadores do Programa do Zoneamento Ecológico-Econômico do Brasil (PZEE), bem como apresenta quatro requisitos: I) compreensão do território, para que se distribuam as atividades conforme as potencialidades e os limites das unidades geoambientais; II) sustentabilidade ambiental para a maximização dos benefícios derivados dos usos dos recursos naturais, conservação ambiental; III) abordagem sistêmica de caráter interdisciplinar para a delimitação dos sistemas ambientais e as zonas e IV) elaboração de cenários para vislumbrar respostas adequadas à escolha de soluções aos problemas (BRASIL, 2003).

No Brasil, o zoneamento é muito usado pelo poder público como instrumento para implementar normas de uso do território nacional. Ressalta-se também, os estudos realiza- 
dos nas universidades e outras instituições que visam o planejamento ambiental e propostas de zoneamentos em diferentes escalas, ampliando o leque de conhecimento sobre o país, as regiões e localidades, bem como, servindo como suporte de relevância científica.

\section{O GEOSSISTEMA E A GEOECOLOGIA DAS PAISAGENS}

Os estudos de geografia física, na década de 1910, influenciados por Emmanuel de Martonne abordavam o quadro natural, dividido em sub-ramos específicos: geomorfologia, climatologia, biogeografia e hidrografia. Assim nesse período, a maioria dos geógrafos físicos não fazia inter-relações entre os elementos naturais das paisagens, reflexo do método positivista predominante na época. A partir dos anos de 1950, influenciados pela geografia nova, os estudos de geografia física são fortemente carregados pela teoria dos sistemas, viabilizando uma análise do ambiente pautado na visão sistêmica (MENDONÇA, 1993).

A Teoria Geral dos Sistemas, que influenciou a criação do conceito de geossistema, foi desenvolvida inicialmente nos Estados Unidos no final dos anos de 1920. Essa teoria forneceu a base para os estudos ambientais, como as propriedades, estruturas, tipos, conteúdo hierarquia e função. Segundo Cavalcanti (2006), a visão sistêmica aproveita os estudos analíticos de cada componente e os integra dentro de um mesmo conjunto, onde são observadas as transformações, distribuição dos sistemas geográficos, dinâmica e conexões. De acordo com Mendonça (1992, p. 41) "a análise de sistemas tem-se configurado como a melhor metodologia da produção de geografia física moderna e contemporânea".

O enfoque sistêmico corresponde à abordagem interdisciplinar, uma concepção metodológica e um meio para o estudo de objetos integrados e das dependências e interações integrais (RODRIGUEZ; SILVA, 2013). Nesses termos, sistema corresponde ao conjunto de unidades organizados e inter-relacionados, que apresentam: elementos ou unidades, relações, atributos, entrada (input) e saída (output) (CHRISTOFOLETTI, 1979).

Nos anos 1960, com aplicação efetiva da geografia para fins de desenvolvimento do Estado Soviético, surge o conceito de geossistema, proposto por Sotchava classificado como uma classe peculiar de sistemas dinâmicos abertos e hierarquicamente organizados. Em tal contexto, o geossistema é a expressão de fenômenos naturais, ou seja, potencial ecológico de determinado espaço no qual há uma exploração biológica, podendo influir fatores sociais e econômicos na estrutura e expressão espacial, porém, sem haver, frente aos processos dinâmicos, uma homogeneidade interna (SOTCHAVA, 1978). Assim, Mendonça (1992, p. 50) apresenta que "a proposição geossistêmica utiliza a análise integrada do complexo físicogeográfico, ou seja, a conexão da natureza com a sociedade humana".

O geossistema foi construído, inspirado no conceito de ecossistema produzido pela ciência biológica, na busca pela utilização do método sistêmico no estudo da natureza. Ross (2009), baseado nos estudos de Sotchava, destaca as diferenças entre ecossistema e geossistema em que o primeiro centra a atenção na vida animal e vegetal com a análise de ecossistema específico, enquanto o segundo considera a inter-relação dos elementos naturais. Segundo Rodriguez, Silva e Cavalcanti (2013), o ecossistema é um conceito monocêntrico, cor- 
responde a um sistema de componentes bióticos e abióticos do qual faz parte os organismos que estão relacionados por processos físicos, químicos e biológicos, já o geossistema é policêntrico, um sistema com organização temporal e espacial complexa formada pela interação pelos elementos físicos que podem ser transformados pela ação antrópica.

No Brasil, o conceito de geossistema foi difundido por Bertrand, baseado na construção do conhecimento sobre a ciência da paisagem e demonstrando que o estudo da paisagem deve basear-se no conceito e nos métodos de geossistema. A noção da paisagem ecológica, introduzida por Troll no final da década de 1930 e a ampliação do conceito de ecossistema de Tansley em 1935, constitui o suporte teórico do geossistema. A abordagem geográfica de paisagem ecológica e, como designada mais tarde, de Geoecologia corresponde ao estudo da paisagem sob o ponto de vista ecológico (ROSS, 2009).

Bertrand em 1978 definiu geossistema como um sistema natural resultado da combinação de fatores físicos, biológicos e antrópicos, caracterizando-o quanto a morfologia, funcionamento e comportamento. Troll na primeira metade do século XX, propôs os fundamentos da ciência da Geoecologia da Paisagem, termo utilizado a partir de 1966, antes denominada de Ecologia da Paisagem que se configurava em duas abordagens: a abordagem da paisagem, responsável pelo estudo da diferenciação espacial da superfície terrestre na interação entre os fenômenos naturais e a abordagem biológica-ecológica encarregada da análise das inter-relações funcionais dos fenômenos naturais e sistemas ecológicos (RODRIGUEZ; SILVA, CAVALCANTI, 2013).

A análise ambiental, a partir de uma visão sistêmica que inter-relacionam os diferentes elementos: naturais, sociais, econômicos e culturais, apresentam-se cada vez mais prósperos na geografia física, oferecendo importante contribuição aos estudos ambientais integrados e interdisciplinares. Nessa perspectiva, destaca-se a Geoecologia das Paisagens, metodologia eficaz para o desenvolvimento de pesquisas geográficas voltadas ao planejamento e gestão ambiental.

A Geoecologia das Paisagens foi influenciada por diferentes correntes filosóficas e escolas nacionais e regionais de pensamento, bem como enfoques de diferentes disciplinas como a Geografia e a Biologia. Um dos principais percursores foi o cientista russo, Dokuchaev, ao utilizar a abordagem ecológica da paisagem para analisar o uso da natureza tendo em vista o homem, além desse, Humboldt, Lomonosov e Troll ofereceram importantes contribuições para a formação dessa metodologia. Destaca-se também a influência da concepção geossistêmica, método sistêmico e a Paisagem Cultural, de Sauer, no século XX (RODRIGUEZ; SILVA, 2013).

A Geoecologia das Paisagens é uma metodologia sistêmica que analisa a relação da sociedade com a natureza, a partir da investigação e interpretação das inter-relações e interações entre os elementos antroponaturais. Segundo Rodriguez e Silva (2013), essa metodologia propicia as bases teóricas e metodológicas para a análise ambiental, servindo como aporte conceitual e procedimental ao planejamento e gestão ambiental.

A Geoecologia das Paisagens é uma ciência ambiental, que oferece uma contribuição essencial no conhecimento da base natural do meio ambiente. Propicia, ainda, fun- 
damentos sólidos na elaboração das bases teóricas e metodológicas do planejamento e gestão ambiental e na construção de modelos teóricos para incorporar a sustentabilidade ao processo de desenvolvimento (RODRIGUEZ; SILVA; CAVALCANTI, 2013, p. 07).

A Geoecologia das Paisagens fundamenta-se em três momentos: I) como se formou e se ordenou a natureza; II) como, a partir das atividades humanas, construíram-se sistemas de uso e de objetos que articulam e determinam a natureza de acordo com suas necessidades e, III) como a sociedade entende a natureza e as transformações derivadas das atividades humanas (RODRIGUEZ; SILVA; LEAL, 2011).

Apoiada na visão sistêmica, a Geoecologia das Paisagens oferece contribuição para a compreensão do quadro natural, socioeconômico e cultural, bem como as inter-relações desses elementos na transformação da paisagem. Rodriguez, Silva e Leal (2011) salientam que essa metodologia permite entender: I) em que grau as sociedades humanas transformam a natureza e a veem no espaço; II) como a sociedade concebe a natureza, o natural e o espaço derivado da natureza e III) como a sociedade percebe a natureza, usa o espaço, a paisagem e o território.

Para compreender os itens listados, a Geoecologia das Paisagens utiliza categorias analíticas: espaço, paisagem e território (Quadro 3) que não são exercidas de maneira isolada, mas interagem entre si e formam à análise geoecológica.

Quadro 3 - Categorias analíticas da Geoecologia das Paisagens

\begin{tabular}{|l|l|}
\hline \multicolumn{1}{|c|}{$\begin{array}{c}\text { CATEGORIAS } \\
\text { ANALÍTICAS }\end{array}$} & \multicolumn{1}{c|}{ DESCRIÇÃo } \\
\hline $\begin{array}{l}\text { Espaço ou Paisa- } \\
\text { gem Natural }\end{array}$ & $\begin{array}{l}\text { Sistema espaço-temporal, uma organização espacial complexa e aberta, for- } \\
\text { mada pela interação entre os componentes biofísicos que podem ser trans- } \\
\text { formados pela atividade antrópica, corresponde ao meio natural de uma vi- } \\
\text { são sistêmica. }\end{array}$ \\
\hline Espaço Geográfico & $\begin{array}{l}\text { Conjunto indissociável, solidário e contraditório de sistemas de objetos e de } \\
\text { ações na superfície do globo terrestre. O espaço geográfico é formado por } \\
\text { objetos naturais, fabricados, técnicos, mecânicos e cibernéticos submetidos à } \\
\text { constituição da sociedade (SANTOS, 1994, 1996). }\end{array}$ \\
\hline Paisagem Cultural & $\begin{array}{l}\text { Fisionomia, morfologia e a expressão formal do espaço e dos territórios, situ- } \\
\text { ada no plano de contato entre os fatos naturais e os fenômenos da ocupação } \\
\text { humana, entre os objetos e os sujeitos que os percebem e agem sobre eles. }\end{array}$ \\
\hline Território & $\begin{array}{l}\text { Conjunto de espaços, paisagens geográficas e sistemas naturais, econômicos, } \\
\text { de habitat e sociais em uma determinada área delimitada pelo poder econô- } \\
\text { mico e político, submetido a um determinado modelo e processo de gestão. }\end{array}$ \\
\hline
\end{tabular}

Fonte: RODRIGUEZ; SILVA; LEAL, 2011.

A Geoecologia das Paisagens realiza a análise das paisagens naturais e antroponaturais com o intuito de resolver os problemas de descaracterização da paisagem, o uso racional dos recursos naturais, a conservação da biodiversidade e geodiversidade, os valores culturais, histórico e estético, pautados no desenvolvimento sustentável. 
Essa fundamentação teórico-metodológica apoia-se em diferentes dimensões, pensamentos, que versam desde as categorias analíticas até a escolha de uma escala de análise que viabilizam a realização de estudos ambientais a partir de uma visão sistêmica, considerando os aspectos naturais, sociais e culturais (FARIAS, 2012). Nesse tocante, percebe-se a relevância dessa metodologia para o desenvolvimento de estudos ambientais em diferentes escalas.

A aplicação da Geoecologia das Paisagens nos estudos ambientais, perpassa pelos objetivos definidos e procedimentos metodológicos de pesquisa organizados, divididos em etapas: organização e inventário, estudos de campo e pesquisa de gabinete. A primeira etapa consiste no levantamento de dados secundários, pesquisa bibliográfica sobre o tema da pesquisa e geocartográfico da área de estudo. Os estudos de campo buscam a obtenção de dados primários, observação, entrevistas e registro fotográfico. A última etapa consiste na análise e intepretação dos dados primários e secundários coletados, produção de mapas temáticos e discussão dos resultados.

Durante a pesquisa de gabinete, divide-se a área de estudo em unidades geoecológicas, definidas como "individualização, tipologia e unidades regionais e locais da paisagem" (RODRIGUEZ; SILVA; CAVALCANTI, 2013, p. 65). Essa compartimentação segue critérios geomorfológicos, devido as suas características, expressarem certo grau de homogeneidade fisionômica, mais claramente perceptíveis na paisagem à visão humana (ROSS, 1997).

Assim posto, executa-se a análise integrada das condições ambientais, geológicas, geomorfológicas, pedológicas, climáticas, hidrológicas e fitogeográficas, bem como socioeconômicas com a descrição dos aspectos populacionais, econômicos, educacionais, culturais, saneamento dentre outras. A partir de então, realiza-se o diagnóstico das formas de uso e ocupação, limitações e potencialidades. A análise integrada dessas variáveis permitirá o conhecimento detalhado da área de estudo visando propostas de ações e diretrizes ao planejamento ambiental, vislumbrado por meio do zoneamento ambiental.

A título de sugestão e segundos os trabalhos de Souza (2006, 2007), Vidal (2014) e Farias (2015) que realizaram propostas de zoneamentos ambientais, propõem-se as zonas: I) de Preservação Ambiental que busca a preservação dos sistemas ambientais, com ênfase para a fauna e flora; II) de Recuperação Ambiental, objetiva a restauração de áreas degradadas e paisagens descaracterizadas; III) de Uso Sustentável, destinadas ao desenvolvimentos de atividades econômicas, agropecuária, extrativismo, industrias dentre outras com o devido controle; IV) de Ordenamento Urbano, abrange as áreas mais urbanizadas e visam controlar a expansão urbana frente aos ambientes mais frágeis e v) de Preservação Cultural que visa a valorização e preservação da identidade cultural.

\section{CONSIDERAÇÕES FINAIS}

A análise ambiental desponta, dentre outros fatores, da necessidade de interligação entre sociedade e natureza na geografia e para tanto, destaca-se a Geoecologia das Paisagens como fundamentação teórico-metodológica eficaz no entendimento das condições socioambientais, dinâmica da paisagem e diagnósticos ambientais pertinentes às propostas de plane- 
jamento ambiental.

Nessa perspectiva, a realização do trabalho apresenta-se como importante contribuição à ampliação do debate acerca dessa temática, ao apresentar o histórico e evolução do conceito de paisagem, definição e diferentes abordagens do planejamento ambiental e o zoneamento como instrumento de organização do meio ambiente, bem como os preceitos teóricos do geossistema e da Geoecologia das Paisagens com ênfase na origem, definição, fundamentos, categorias analíticas e aplicabilidade dessa metodologia.

Ressalta-se que os procedimentos metodológicos apontados, podem ser usados para a análise ambiental de diferentes áreas de estudos, aplicadas em realidades variadas. Pesquisas posteriores deverão aperfeiçoar a discussão realizada e os procedimentos de pesquisa demonstrados.

\section{REFERÊNCIAS}

BRASIL. Ministério do Meio Ambiente. Programa do Zoneamento Ecológico-Econômico: diretrizes metodológicas. 2. ed. Brasília, 2003.

CAVALCANTI, A. P. B. Métodos e técnicas da pesquisa ambiental. Teresina: UFPI, 2006. CHRISTOFOLETTI, A. Análise de sistemas em Geografia. São Paulo: Hucitec, 1979.

FARIAS, J. F. Aplicabilidade da geoecologia das paisagens no planejamento ambiental da bacia hidrográfica do rio Palmeira-Ceará, Brasil. Fortaleza, 2015, 222f. Tese (Doutorado em Geografia) Universidade Federal do Ceará, Fortaleza, 2015.

Zoneamento geoecológico como subsídio para o planejamento ambiental no âmbito municipal. Fortaleza, 2012, 190 f. Dissertação (mestrado em Geografia) Universidade Federal do Ceará, Fortaleza, 2012.

GOMES, P. C. da G. Geografia e modernidade. 2 ed. Rio de Janeiro: Bertrand, 2000.

MENDONÇA, F. Geografia e meio ambiente. São Paulo: Cortez, 1993.

Geografia física: ciência humana? 3 ed. São Paulo: Cortez, 1992.

RODRIGUEZ, J. M. M.; SILVA, E. V. da. A classificação das paisagens a partir de uma visão geossistêmica. Revista Mercator. ano 1, n. 1, 2, Fortaleza, p. 95-112, 2002.

Planejamento e gestão ambiental: subsídios da geoecologia das paisagens e da teoria geossistêmica. Fortaleza: Edições UFC, 2013.

RODRIGUEZ, J. M. M; SILVA, E. V. da; CAVALCANTI, A. P. B. (orgs.) Geoecologia das Paisagens: uma visão geossistêmica da análise ambiental. 4 ed. Fortaleza: Edições UFC, 2013.

ROSS, J. L, S. Ecogeografia do Brasil: subsídios para planejamento. São Paulo: Oficina de texto, 2009.

. Geomorfologia: ambiente e planejamento. 4 ed. São Paulo: Contexto, 1997.

SALES, V. C. Geografia, sistemas e análise ambiental: abordagem crítica. GEOUSP: Espaço e tempo. São Paulo, n. 16, 2004, p. 131-141.

SANTOS, R. F. dos. Planejamento ambiental: teoria e prática. São Paulo: Oficina de Textos, 2004.

SAUER, C. O. A morfologia da paisagem. In: CORRÊA, R. L.; ROSENDHL, Z. Paisagem, tempo e 
cultura. Rio de Janeiro: EdUERJ, 1998.

SILVA, E. V. da; RODRIGUEZ, J. M. M.; LEAL, A. C. planejamento ambiental em bacias hidrográficas. In: SILVA, E. V. da; RODRIGUEZ, J. M. M.; MEIRELES, A. J. de A. Planejamento ambiental e bacias hidrográficas. Tomo 1. Fortaleza: Edições UFC, 2011.

SOTCHAVA, V. B. Por uma teoria de classificação de geossistemas de vida terrestre. Biogeografia. São Paulo, n. 14, 1978.

SOUZA, M. J. N. de; OLIVEIRA, V. P. V. de. Análise ambiental: uma prática da interdisciplinaridade no ensino e na pesquisa. Revista Rede. Fortaleza, v. 7, n. 2. p. 42-59, 2011.

SOUZA, M. J. N. de. et al. Zoneamento ecológico-econômico das áreas de influências do reservatório da Barragem Castanhão-Ceará. CETREDE/UFC/DNOCS. Fortaleza, 2006.

. Zoneamento ecológico-econômico do bioma caatinga e serras úmidas do estado do Ceará. FCPC/UFC/SEMACE. Fortaleza, 2007.

VIDAL, M. R. Geoecologia das Paisagens: fundamentos e aplicabilidades para o planejamento ambiental no baixo curso do rio Curu-Ceará/Brasil. Fortaleza, 2014, 191f. Tese (Doutorado em Geografia). Universidade Federal do Ceará. Fortaleza 2014.

VITTE, A. C. O desenvolvimento do conceito de paisagem e a sua inserção na geografia física. Revista Mercator, Fortaleza, ano 06, n. 11, p. 71-78, 2007.

Artigo recebido em 01 de março de 2018.

Aprovado em 24 de abril de 2018. 